\begin{tabular}{|c|c|c|}
\hline 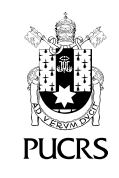 & $\begin{array}{l}\text { ESCOLA DE } \\
\text { HUMANIDADES }\end{array}$ & $\begin{array}{l}\text { Revista Digital do Programa de Pós-Graduação em Letras da PUCRS } \\
\text { Letrônica, Porto Alegre, v. 13, n. 2, p. 1-9, abr.-jun. } 2020 \\
\text { e-ISSN: } 1984-4301\end{array}$ \\
\hline 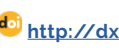 & $\mathrm{rg} / 10.15448 / 1984-4301.2020 .2 .36120$ & \\
\hline
\end{tabular}

\title{
Aquilo que não pode deixar de ser dito: o efeito de pré-construído do discurso machista
}

\author{
That which cannot be left unsaid: the preconstructed effect of the male discourse
}

Bruna Vitória Tejada ${ }^{1}$

orcid.org/0000-0002-1194-2402 brunaatejada@gmail.com

Luciana lost Vinhas ${ }^{1}$

orcid.org/0000-0003-1026-2277

lucianavinhas@gmail.com

Recebido em: 26 out. 2019 Aprovado em: 9 dez. 2019. Publicado em: 13 ago. 2020
Resumo: Este trabalho propõe-se a um gesto de interpretação assentado nos princípios teóricos da Análise de Discurso de tradição francesa. Com interesse particular na noção de pré-construído, elaborada por Paul Henry e desenvolvida por Michel Pêcheux, objetiva-se pesquisar como ele é reproduzido como um saber que todo mundo sabe, à revelia da formação discursiva com a qual o sujeito se identifica. Assim, o pré-construido é entendido como um saber universal; mesmo que o sujeito não se identifique com esse saber, ele pode invadir seu discurso. Atraídas pelas relações de gênero estabelecidas em nossa formação social, buscamos identificar irrupções do discurso hegemônico patriarcal sob a forma de pré-construidos em discursos tidos como subversivos. O corpus selecionado para análise é constituido por materialidades verbais e não verbais e foi coletado no site de rede social Facebook. Para a análise dos aspectos imagéticos, tem-se por base os estudos de Quevedo (2012), que vê na imagem efeitos similares aos do texto escrito.

Palavras-chave: Análise do Discurso. Pré-construido. Gênero.

Abstract: This paper aims to establish a gesture of interpretation based on the theoretical principles of the French Discourse Analysis. Particularly interested in the notion of preconstructed, created by Paul Henry and developed by Michel Pêcheux, the objective is to research how the preconstructed is reproduced as a knowledge that everybody knows, despite the discursive formation with which the subject is identified to. Thus, the preconstructed is understood as a universal knowledge; even if the subject is not identified with the preconstructed, it can invade the subject's discourse. Driven by the relations of gender stablished in our social formation, we aim to identify the irruption of the hegemonic patriarchal discourse through the shape of a preconstructed in discourses considered subversive. The corpus that is analyzed is constituted by verbal and non verbal elements, and it was taken from the Facebook social media network. For the analysis of the verbal and non verbal elements, we are based on the studies developed by Quevedo (2012). The author understands tha the image has similar effects considering the written text. Keywords: Discourse Analysis. Preconstructed. Gender.

\section{Introdução}

Diante do interesse particular pelos discursos concernentes às relações de gênero, mais especificamente por aqueles que se referem à heteronormatividade, propomos analisar, com base nos fundamentos teórico-metodológicos da Análise de Discurso pêcheuxtiana, discursos que aparentemente subvertem a ideologia androcêntrica cristalizada em nossas configurações sociais. Tais discursos, em sua superfície, ressaltam as conquistas das mulheres frente à posição subjugada que ocupam em nossa formação social atual; no entanto, causa-nos estranhamento inserilos em uma posição discursiva subversiva de afirmação da igualdade de gênero. Partimos da hipótese de que, em muitos casos, a ideologia 
do patriarcado irrompe nesses discursos apesar de, aparentemente, se posicionarem a favor do feminismo. Essa invasão do impensado no discurso, invasão de um saber fora da formação discursiva de identificação, mas que é universal e está "sempre já ai", como diz Pêcheux (1997), caracteriza o funcionamento da noção de pré-construido.

Procuramos entender como pré-construídos da ideologia hegemônica se inserem nas formações discursivas subversivas. Por formação discursiva subversiva entendemos os discursos que rompem coma formação discursiva dominante: se a formação discursiva dominante é a machista, a formação discursiva subversiva, e dominada, é a feminista, ou uma formação discursiva pró igualdade de gênero. Pelo caráter invasivo e universal dos préconstruidos, julga-se necessário denunciar o préconstruido machista, pois ele irrompe até mesmo em formações discursivas antagônicas e, assim, sua perpetuação é assegurada tanto pela formação discursiva de identificação quanto pela formação discursiva subversiva. Para isso, faz-se necessário trazer estudos atinentes às relações de gênero para discussão e compreensão das especificidades do funcionamento do pré-construido e sua relação com a Análise de Discurso.

Com base nesses pressupostos, o presente artigo apresenta a análise de uma publicação feita na rede social online Facebook em um grupo de mulheres. A publicação, em um primeiro momento, pode se inscrever em uma posição de identificação com o discurso feminista; contudo, após o movimento de teorização e de interpretação feito sobre o corpus, identificamos o atravessamento de um discurso advindo de outro lugar, o que nos remete ao funcionamento do pré-construido determinando as condições de reprodução da ideologia dominante.

Importante ressaltar que, com essa proposta de trabalho, avançaremos nas tentativas de abordar o gênero a partir de uma perspectiva discursiva, compreendendo-o em suas relações sócio-históricoideológicas. Isso será feito na primeira parte do trabalho, referente aos princípios teóricos. Em seguida, traremos as considerações teóricas sobre a noção de pré-construído no arcabouço teóricoanalítico da Análise de Discurso, para, depois disso, tratar sobre a análise discursiva de imagens. $\mathrm{Na}$ construção das análises, partiremos do processo de dessintagmatização da superficie linguistica do corpus discursivo e, para a leitura das imagens, seguindo Quevedo (2012), teremos como partida a decomposição das imagens em secções discursivas. A descrição e a análise do corpus serão desenvolvidas na terceira parte do texto, para, finalmente, passarmos às nossas considerações finais.

\section{Princípios teóricos}

\subsection{0 gênero por uma perspectiva discursiva}

As figuras de homem e mulher são construções culturais modeladas por normas sociais simbólicas geralmente originárias do falocentrismo. Neste estudo, entendemos gênero como uma das determinações políticas que organizam as relações de poder, controle e subjugação². Essa categoria permite aos homens a dominação e impõe às mulheres a submissão. Ela é assentada em uma sociedade androcêntrica e heteronormativa que naturalizou essa relação impedindo seu reconhecimento e a consequente mudança de cenário.

Por heteronormatividade fazemos referência às normas sociais cristalizadas pela ideologia hegemônica, que estabelece posições de privilégios entre sujeitos em função de seu sexo ou gênero de identificação, agindo na produção e manutenção de estereótipos sexistas e heterossexuais. Pela heteronormatividade, segundo Martins (2017, p. 174), as relações de gênero e sexuais estabelecem a hierarquização dos exercícios de poder, sendo elas "subjetivadas sob supostas identidades estáveis, fixas e essencializadas, e que desconsideram o caráter histórico, cultural, social, econômico e performativo destas relações".

Conforme Strey (2012), um dos aspectos estruturais da desigualdade de gênero é a divisão laboral baseada no gênero, que relega aos homens a esfera pública da sociedade e às mulheres a esfera privada, restringindo seus

2 É necessário frisar que há ainda outras determinações que organizam as relações de poder, como classe social e etnia. 
espaços de circulação. O trabalho doméstico, por ser realizado no interior do lar, fora do ambiente público, não é considerado trabalho, não sendo remunerado. Ele é, predominantemente, executado por mulheres, o que lhes imputa uma dupla jornada de trabalho quando elas ainda possuem um trabalho remunerado fora de casa. Strey (apud GROSSI, 2012, p. 55) diz que

Devido a que a economia e a política, mais do que a família, se convertem nas instâncias centrais das sociedades modernas, essa divisão do trabalho, as prioridades e responsabilidades produzem desigualdades de poder entre os gêneros. Por sua parte, o maior poder acumulado pelos homens se reflete em uma variedade de outras diferenças e desigualdades, assim como também reforça a divisão sexual do trabalho.

A resistência das mulheres à ideologia androcêntrica permitiu-lhes significativos avanços na busca pela igualdade de gênero, assegurando sua ascensão a posições historicamente ocupadas por homens. Em nosso corpus, conforme será discutido, temos a figura da mulher policial, que emerge no Brasil apenas na década de 1950 e destinava-se à proteção das mulheres e jovens. Apesar de contínuos avanços pela igualdade no setor laboral, dados do Instituto Brasileiro de Geografia e Estatística (IBGE) 3 apontam para a desigualdade salarial entre homens e mulheres. Com base na Pesquisa Nacional por Amostra de Domicilios Contínua (PNAD Contínua), divulgada em março de 2019, há uma disparidade salarial de 20,5\% entre homens e mulheres. A menor discrepância salarial observada encontra-se entre os professores de ensino fundamental (9.5\%) e as maiores no setor comercial entre gerentes, varejistas e atacadistas (34\%) e no setor da agricultura (35,8\%).

O fenômeno da opressão parece-nos fundamental para compreender as relações de gênero. Por opressão fazemos referência "a todas as formas de controle que impedem o completo avanço e o preenchimento das metas de um individuo" (GROSSI; AGUINSKY, apud GROSSI, 2012, p. 31). Desataca-se o caráter multifacetado das opressões, que permite a experimentação dos sujeitos a "diferentes formas de opressão de acordo com o seu 'lugar social'" (GROSSI; AGUINSKY apud GROSSI, 2012, p. 31). Desse modo, essa relação de domínio sobre o outro tem diversos pretextos: assentam-se no gênero, na sexualidade, na etnia ou na classe social; todos, no entanto, compartilham o objetivo de manter os privilégios da classe dominante, perpetuando as relações vigentes entre homens e mulheres, heterossexuais e LGBTs brancos e negros, ricos e pobres. Atendendo aos pressupostos da ideologia dominante, esse processo naturalizou-se de tal modo em nossa sociedade que beira a invisibilidade.

Frente à reprodução das relações de força que acontece via interpelação ideológica, a resistência exerce papel fundamental na busca pela subversão ao instituido. É pelo processo de interpelação-identificação ideológica que o sujeito se constitui; porém, conforme Pêcheux (1997), todo ritual é passivel de falhas, permitindo ao sujeito rebelar-se. Entendemos que os movimentos feministas surgem como resistência à dominação patriarcal, instaurando uma mudança nas relações de dominância. Segundo Zoppi-Fontana e Ferrari (2017, p. 10),

\begin{abstract}
A partir do questionamento dos espaços da política e do privado, o feminismo produziu um acontecimento histórico e, desta forma, rompeu o circulo de repetição da condição das mulheres na sociedade. Os discursos feministas se caracterizam por reunir, convencer. organizar e politizar as mulheres, tornando-as visiveis para si mesmas e convidando-as à constituição de coletivos de luta.
\end{abstract}

As autoras dizem que esse cenário de questionamento e subversão à ideologia hegemônica é fecundo para os estudos da linguagem e, em filiação à teoria de Pêcheux, não poderiamos ignorar tais fenômenos que nos permitem "desenvolver indagações sobre o aparelho conceitual e os procedimentos analíticos organizados em torno à questão dos processos de interpelação ideológica que constituem o sujeito do discurso" (ZOPPI-FONTANA; FERRARI, 2017, p. 8).

A noção de formação imaginária nos permite 
pensar a modulação das práticas do sujeito de acordo com as identificações de gênero que "trabalham os processos imaginários de reconhecimento/desconhecimento que constituem os sujeitos nas suas relações sociais" (ZOPPI-FONTANA; FERRARI, 2017 p. 14). A sociedade deposita nas mulheres uma série de expectativas em função de seu sexo biológico, e isso tem efeitos no processo de interpelação ideológica. Quando as formações imaginárias moldadas pela ideologia hegemônica não são reproduzidas, quando as mulheres não se encaixam no perfil cultural de feminilidade e buscam a subversão ao cristalizado, há a rejeição destas pela formação social, hegemonicamente machista. Essa rejeição manifesta-se através do enfrentamento a diferentes tipos de violência contra a mulher. Perante este cenário, julgamos importante desnaturalizar as relações de gênero, não entendendo que as pessoas do sexo feminino devem se reconhecer como representantes de uma feminilidade ideologicamente determinada, ao mesmo tempo não entendendo que as pessoas do sexo masculino não são imagens estereotípicas do homem em posição dominante. Para isso, é fundamental denunciar discursos machistas, pois nestes estão materializados os pressupostos dessa ideologia, reproduzida até mesmo por mulheres que, ao não perceberem sua submissão ao discurso patriarcal hegemônico, se aliam a práticas que o reproduzem na formação social.

\subsection{0 pré-construído na Análise de Discurso}

Neste trabalho, interessamo-nos particularmente pela noção de pré-construido. Esse termo foi utilizado pela primeira vez pelo filósofo Paul Henry, em 1975, na revista Langages, em seu estudo sobre as construções relativas. Henry caracteriza o pré-construído como o efeito de anterioridade característico das relativas determinativas. Em evento organizado pelo Laboratório de Estudos Urbanos, junto com Centro de Pesquisa PoEHMaS, o autor diz que a noção de pré-construido é central na Análise de Discurso, pois interroga as relações entre língua e discurso dentro da AD. ${ }^{4}$
Michel Pêcheux desenvolve o conceito de pré-construido a partir dos estudos de Frege sobre as relativas, identificando neste indícios da relação entre o funcionamento da língua e o funcionamento do pensamento. De acordo com Pêcheux (1997, p. 96), para Frege "o funcionamento da língua (no caso, a relação entre independente e subordinada relativa) induz no 'pensamento' uma ilusão". Essa ilusão seria resultado de uma imperfeição da linguagem natural que, por ser "mal feita", "contém armadilhas e ambiguidades que podem desaparecer numa língua artificial 'bem feita'" (PÊCHEUX, 1997, p. 97). Da relação entre o pensamento, que corresponde à proposição em seu todo, e o objeto do pensamento, que corresponde à subordinada da proposição, decorre "a ilusão por meio da qual esse objeto de pensamento induz, necessariamente, no pensamento, a existência de alguém, não de um modo geral, mas como sujeito absolutamente único" (PÊCHEUX, 1997, p. 98, grifo do autor).

Pêcheux refuta essa ideia com base no exemplo "aquele que salvou o mundo morrendo na cruz nunca existiu". Seguindo Frege, a presença do discurso ateu que nega a subordinada deveria prejudicar a compreensão do sentido, uma vez que nega a proposição; no entanto, o autor refere que isso não acontece, pois, a frase é compreensivel e provida de sentido. Sobre a proposta de Frege, Pêcheux questiona: "não deveriamos, ao invés disso, considerar que há separação, distância ou discrepância na frase entre o que é pensado antes, em outro lugar ou independentemente, e o que está contido na afirmação global da frase?" (PÊCHEUX, 1997, p. 99, grifo do autor).

Assim, na relativa determinativa, evidencia-se a relação "entre 'dois domínios de pensamento', de modo que um elemento de um domínio irrompe em um elemento do outro sob a forma do que chamamos 'pré-construído', isto é, como se esse elemento já se encontrasse ai" (PÊCHEUX, 1997, p. 99, grifo do autor). É por isso que podemos aproximar o trabalho do préconstruído ao funcionamento do esquecimento $n^{\circ}$ 1 , considerando que se trata de um funcionamento

4 O video completo do evento está disponivel em: https://www.youtube.com/watch?V=nO3lF7v7qHg. Acesso em: 15 out. 2019. 
que ultrapassa qualquer tentativa de controle do sujeito sobre aquilo que enuncia.

O efeito de pré-construido é oriundo do interdiscurso, definido por Pêcheux (1997) como "o todo complexo com dominante". É no interdiscurso que se encontram todos os discursos disponiveis para a delimitação das formações discursivas. Entende-se por pré-construido, portanto, os "já-ditos", os discursos anteriores que funcionam produzindo um efeito de evidência de sentido.

Pêcheux (1997, p. 102) destaca como característica do pré-construído:

[...] a separação fundamental entre o pensamento e o objeto de pensamento, com a pré-existência deste último, marcada pelo que chamamos uma discrepância entre dois domínios de pensamento, de tal modo que o sujeito encontra um desses domínios como o impensado de seu pensamento, impensado este que, necessariamente, pré-existe ao sujeito.

De acordo com Pêcheux (1995, p. 164), "o 'pré-construido' corresponde ao "sempre-já-aí" da interpelação ideológica que fornece-impõe a "realidade" e seu "sentido" sob a forma da universalidade"; desse modo, ele é naturalizado e compartilhado socialmente. Para Maldidier (2003), a noção de pré-construido é fundamental para a Análise de Discurso, pois funciona como um elo entre a teoria do discurso e a linguistica. Segundo a autora, o pré-construido "fornece a ancoragem linguística da tomada do interdiscurso" (MALDIDIER, 2003, p. 34).

A partir desses elementos, é possivel estender o trabalho do pré-construido para outras formas de existência material, não sendo restrito à língua. $\mathrm{Na}$ nossa análise, vamos empreender uma proposta de o pré-construído emergir no funcionamento do discurso materializado em um texto verbal e não verbal: uma publicação de Facebook que articula uma imagem a uma legenda.

\subsection{Sobre a análise discursiva de imagens}

Para proceder à análise do corpus selecionado, fazse necessário buscar suporte teórico sobre análise de imagens 5 em Quevedo (2012). De acordo com o autor, a imagem tem funcionamento similar ao texto, "submetendo-se aos mesmos efeitos mormente considerados quanto ao texto escrito, como efeito de evidência, de literalidade, de completude, de não contradição, dentre outros" (QUEVEDO, 2012, p. 194).

A questão da materialidade em sua forma imagética ainda é explorada no seguinte excerto retirado de Quevedo (2012, p. 194):

\begin{abstract}
Postulamos ainda que, assim como o texto escrito pode ter uma materialidade (formulação) visual [..], o texto visual pode estar acompanhado de outras materialidades (formulações): verbal escrita, verbal sonora, gestual, cinética etc. Nesse sentido, assim como nos preocupamos em categorizar um discurso quanto ao campo, tipo ou suporte, preferimos evitar o uso de sintagmas como o "discurso visual", o "discurso imagético" ou o "discurso da imagem". Entendemos que a imagem não tem ou não é de per si um discurso; é-lhe uma materialidade.
\end{abstract}

Partindo de uma perspectiva discursiva, o autor significa o termo imagem como "o resultado da produção de um recorte no imaginário acerca de X (ilusões subjetiva e referencial) - projeções (auto)identitárias ou referenciais que, sendo ou não simbolizadas, produzem efeitos materiais" (QUEVEDO, 2012, p. 101). O termo imagem é utilizado como "produção de uma leitura", diferenciandose da imagem como objeto empírico. O senso comum atribui à imagem um caráter de evidência; no entanto, a evidência é ilusória, ou seja, diz respeito a uma representação imaginária, forjada ideologicamente. A imagem deve ser relacionada ao seu contexto sócio-histórico-ideológico e ao sujeito interpelado ideologicamente, pois, assim como os sentidos não estão presos às palavras, eles tampouco estão presos à imagem enquanto objeto empírico em seu efeito de evidência.

Para a análise de imagens, Quevedo (2012, p. 140) estabelece o conceito de secção discursiva (SD), em referência à sequência discursiva, "visto que (i) não cabe a noção de linearidade de leitura implicada pelo termo "sequência" e (ii) a discriminação de elementos constituintes da imagem é uma operação de recorte do analista, que secciona a

\footnotetext{
5 Embora existam vários estudos, no âmbito da Análise de Discurso, que trabalham com a análise discursiva de imagens, priorizamos neste recorte, enfocar na elaboração teórica desenvolvida por Quevedo (2012) em função dos objetivos do trabalho. Citamos, por exemplo, a contribuição de Suzy Lagazzi, através da noção de materialidade significante, para o desenvolvimento da questão.
} 
imagem em partes que julga relevantes destacar". Nas análises do texto verbal parte-se do processo de dessintagmatização da superfície linguística; em paralelo, nas análises de imagem, opera-se a decomposição em secções discursivas.

\section{Análise do corpus}

Para análise do corpus selecionado, é necessário proceder à interpretação do material de análise constituido por elementos verbais e não verbais, uma vez que correlacionam-se constituindo os sentidos.

Figura 1 - Imagem do Perfil pessoal na plataforma do Facebook

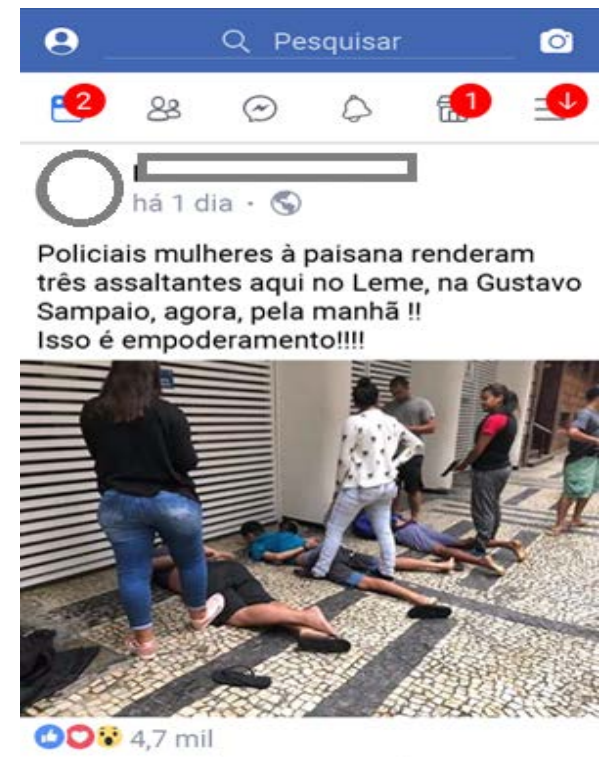

Fonte: Perfil pessoal na plataforma Facebook que publicou a postagem em fevereiro de 2019 sob modo público. ${ }^{6}$

Na análise da Figura 1, nosso gesto descritivo e interpretativo empreendeu a secção da imagem da publicação nas seguintes sequências e secções discursivas (SDs), sendo as sequências referentes ao recorte de elementos verbais e as secções referentes ao recorte de elementos não verbais:

a) secção discursiva 1 (SD1) - três mulheres em pé e portando arma de fogo;

b) secção discursiva 2 (SD2) - três homens rendidos deitados no chão; c) sequência discursiva 3 (SD3) - "Policiais mulheres à paisana renderam três assaltantes aqui no Leme, na Gustavo Sampaio, agora, pela manhã!!";

d) e sequência discursiva 4 (SD4) - "Isso é empoderamento!!!!".

Há, na imagem, mulheres exercendo um trabalho historicamente atribuido aos homens. A publicação associa esse gesto ao "empoderamento feminino", através das conquistas adquiridas pelas mulheres ao longo da luta contra o sistema patriarcal. Junto com a imagem, temos o enunciado "Policiais mulheres à paisana renderam três assaltantes" e, em seguida, o enunciado "Isso é empoderamento!!!!". A relação estabelecida entre as policiais e os assaltantes rendidos, caracterizada de empoderamento, causa-nos estranhamento, pois, onde esperava-se encontrar a redução das desigualdades de gênero, há uma relação constituída pela violência, pelo discurso intolerante, considerando que a publicação foi feita em um grupo que se autorrepresenta como feminista. Os assaltantes apresentam-se deitados com os rostos voltados para o chão, descalços e com armas de fogo apontadas em direção a eles, em uma relação de poder e submissão.

É necessário, então, tratar brevemente sobre o estranhamento na Análise de Discurso, pois o efeito de sentido produzido pelas secções discursivas é interpretado como não coincidente com o efeito de sentido estabelecido pelas sequências discursivas, existindo, portanto, uma contradição, o que caracteriza o efeito de pré-construido (como uma intrusão de algo estranho naquilo que é dito). Ernst (2009, p. 4) conceitua o estranhamento como

Estratégia discursiva que expõe o conflito entre formações discursivas e consiste na apresentação de elementos intradiscursivos - palavras, expressões e/ou orações - e interdiscursivos, da ordem do ex-cêntrico, isto é, daquilo que se situa fora do que está sendo dito, mas que incide na cadeia significante, marcando uma desordem no enunciado. [...] Possui como caracteristicas a imprevisibilidade, a inadequação e o distanciamento daquilo que é esperado. 
Marinho e Gonçalves (2016), em levantamento acerca do conceito de empoderamento nos estudos de gênero, dizem que este é um conceito fluido, mas, via de regra, versa sobre as mudanças estruturais nas relações de poder da sociedade, com vistas à eliminação das relações de dominância. O empoderamento pode se apresentar em nivel individual; no entanto, a maioria dos estudos referentes à temática o abordam pela perspectiva coletiva. Segundo as autoras,

Na perspectiva dos estudos de gênero, é consenso entre as autoras mais utilizadas nos debates sobre empoderamento que este se refere a um desafio às relações de poder e a uma busca pela obtenção de maior controle sobre as fontes de poder. Ao considerar a existência de relações desiguais de gênero, o empoderamento feminino pode ser definido, em termos bastante amplos, como um processo de superação da desigualdade de gênero (MARINHO; GONÇALVES, 2016, p. 82).

No nivel da formulação, na SD4, temos o enunciado afirmativo contendo o pronome demonstrativo "isso", que está demonstrando/ determinando o que é o empoderamento feminino. O demonstrativo estabelece uma relação de anáfora verbal e não verbal, estabelecendo referência tanto com as secções discursivas (SD1 e SD2) quanto com a sequência discursiva anterior (SD3). O empoderamento, neste caso, advém da prática das condutas masculinas pelas mulheres, ou seja, ele surge pelo uso do poder e da força para render. Nesse enunciado, irrompe o pré-construido machista, que só permite a ascensão das mulherese só legitima o feminismo destas quando elas adotam práticas masculinas respeitadas socialmente, as quais envolvem uma relação de dominação ao invés de serem estabelecidas com base na igualdade de direitos. Sabe-se que as mulheres sofrem preconceito quando nestas posições; no entanto, existe um imaginário acerca de o que é um policial que cola na memória e associa-se às policiais. Marinho e Gonçalves (2016), respaldadas em Léon (2001), afirmam que
O empoderamento não é um processo linear com início e fim definidos de maneira igual para diferentes grupos de mulheres: "El empoderamiento es diferente para cada individuo o grupo según su vida, contexto e historia, y según la localización de la subordinación en lo personal, familiar, comunitario, nacional, regional y global" (León 2001, 104) (MARINHO; GONÇALVES, 2016, p. 83).

A forma como esse discurso significa empoderamento advém do discurso machista, substituindo a subjugação das mulheres aos homens, pela subjugação dos homens às mulheres. As relações estabelecidas se dão de uma ou outra forma por meio de intolerância, violência e submissão. É interessante que tal imagem tenha sido compartilhada até mesmo no grupo "Mulheres Unidas Com o Brasil", criado em 2018 e originalmente intitulado "Mulheres Unidas Contra Bolsonaro", reação aos discursos machistas proferidos pelo então candidato à presidência. 0 grupo, atualmente, conta com mais de dois milhões de membros (2.467.928) e a postagem, até fevereiro de 2019, recebeu 14.787 curtidas, 767 comentários e foi compartilhada 51 vezes. Esses números apontam para uma relação de identificação dos membros do grupo com o discurso em questão.

Figura 2 - Imagem do grupo Mulheres Unidas Com o Brasil

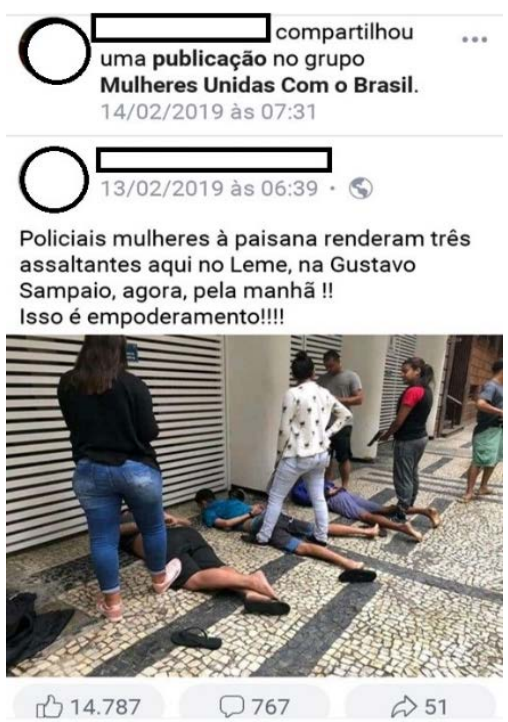

Fonte: Postagem sob o modo público no Grupo Mulheres Unidas Com o Brasil, criado na plataforma Facebook? 
A partir da Figura 2, percebe-se, no discurso analisado, uma posição-sujeito que remete a uma formação discursiva feminista, subversiva do discurso hegemônico patriarcal, o qual restringe ou impede às mulheres a execução de determinadas funções atribuidas historicamente aos homens por suas caracteristicas biológicas ou emocionais entendidas como mais fortes e estáveis. No entanto, a FD subversiva é atravessada pelo préconstruido atravessado pela posição discursiva dominante na nossa formação social. Esse préconstruido caracteriza o empoderamento e o limita a determinadas condutas respeitadas pela sociedade, marginalizando o que não está nesse perfil. É nessa invasão do impensado no discurso, invasão de um saber fora da FD de identificação, mas que está sempre já aí, que encontramos no funcionamento discursivo do pré-construido. Este irrompe na FD como uma denúncia de seu caráter heterogêneo, delimitado por fronteiras fluidas.

Ao produzir discursos que definem de forma tão reduzida o processo de empoderamento feminino, ignorando que este se dá de diversas formas para diversos grupos de mulheres, deixamse à margem mulheres que não se encaixam nesse perfil, tais como aquelas que protestam nuas e são constantemente rechaçadas por não se encaixarem no perfil convencional de mulher, tendo seus protestos deslegitimados por não se coadunarem ao que se convencionou como empoderamento. Cortez e Souza (2008, p. 172), distante de um reducionismo, e ao encontro de uma perspectiva política sobre o empoderamento das mulheres, nos dizem que:

O empoderamento implica, pois, no reconhecimento das restrições sociais a que a categoria está submetida e da necessidade de reversão dessa situação, por meio de mudanças em um contexto amplo/público (inserção em cargos de poder/decisão, educação não sexista e serviços de saúde adequados) e também em contextos mais especificos, ou individuais (aumento de auto-estima e autonomia, reorganização do trabalho doméstico, etc).

A irrupção do pré-construido estabelece uma contradição no discurso em questão. Segundo Courtine (2009), a contradição se faz presente nas formações discursivas por seu caráter heterogêneo e fluido, a FD é heterogênea na medida em que ela integra elementos provenientes de seu exterior. Para Zoppi-Fontana e Ferrari (2017, p. 8), a problemática das mulheres permite-nos a reflexão sobre a "contradição constitutiva dos processos de produção de sentido e do sujeito, que tanto reforçam o imaginário social quanto irrompem como acontecimento, abrindo brechas sociais e discursivas para o deslocamento de sentidos e a emergência de novas modalidades de identificação".

Uma faceta perversa do discurso patriarcal é a utilização de suas próprias vítimas em sua legitimação e perpetuação. Ao não perceber sua submissão à ideologia misógina hegemônica, as mulheres reproduzem discursos machistas e disseminam seus pressupostos.

\section{Considerações finais}

A categoria gênero apresenta-se como um espaço permeado por pré-construidos culturais característicos da heteronormatividade. Estes são universais e apresentam-se como naturais, invadindo diferentes formações discursivas. No trabalho desenvolvido, constatamos uma não coincidência entre a representação imaginária do sujeito que reproduz a publicação e o efeito de sentido que ela provoca, pois, além de promover o discurso intolerante aos homens, a publicação resgata saberes de subjugação e humilhação, próprios da ideologia machista dominante.

Pretendemos, com a execução deste trabalho e com a seleção do corpus discursivo, interpretar sequências compartilhadas na rede social Facebook. Essas sequências eram utilizadas como características de empoderamento e subversão à ideologia patriarcal. No entanto, através de nosso gesto interpretativo, percebemos que préconstruidos da ideologia dominante irrompem. Os discursos relacionados às mulheres são permeados por pré-construidos característicos da heteronormatividade. Estes são universais e apresentam-se como naturais, invadindo diferentes formações discursivas.

É fundamental destacar a importância de desnaturalizar o caráter de evidência da imagem. $\mathrm{Na}$ leitura do corpus discursivo podemos 
construir sentidos que não estavam em um plano superficial. De acordo com Orlandi (2015), a Análise de Discurso nos coloca em estado de reflexão, buscamos por meio de seus princípios desnaturalizar a evidência do sujeito e a evidência do sentido construindo, como propõe a autora, uma relação menos ingênua com a linguagem.

\section{Referências}

CORTEZ, Mirian Béccheri; SOUZA, Lidio de. Mulheres (in)Subordinadas: o Empoderamento Feminino e suas Repercussões nas Ocorrências de Violência Conjugal. Psicologia: Teoria e Pesquisa,Brasilia, v. 24 n. 2, p. 171-180, 2008. https://doi.org/10.1590/S010237722008000200006

COURTINE, Jean-Jacques. Análise do discurso politico: o discurso comunista endereçado aos cristãos. São Carlos: EDUFSCAR, 2009.

ERNST-PEREIRA, A. A Falta, o Excesso e o Estranhamento na Constituição/Interpretação do Corpus Discursivo. In: SEMINÁRIO DE ESTUDOS EM ANÁLISE DE DISCURSO - SEAD, IV., Porto Alegre, 2009. Anais do IV SEAD, Porto Alegre: UFRGS, p.1-6, 2009. https://doi.org/10.5335/rdes.vgi2.3851

ERNST, Aracy; QUEVEDO, Marchiori. Pré-construido e discurso transverso: ferramentas de derrisão em uma charge de Latuff. Revista do Programa de Pós-Graduação em letras da Universidade de Passo Fundo, v. 9, n. 2, p. 325-339, jul./dez. 2013.

GROSSI, Patricia Krieger; AGUINSKY, Beatriz Gershenson. Por uma nova ótica e uma nova ética. In: GROSSI, Patrícia Krieger. Violências e Gênero: coisas que a gente não gostaria de saber. Porto Alegre: EDIPUCRS, 2012. p. 25-50.

HENRY, Paul. Construções relativas e articulações discursivas. Cadernos de Estudos da Linguagem, Campinas, n. 19, p. 43-64, jul./dez. 1990.

MALDIDIER, Denise. A inquietação do discurso: (re) ler Michel Pêcheux hoje. Campinas: Pontes, 2003.

MARINHO, Paloma Abelin Saldanha; GONÇALVES, Hebe Signorini. Práticas de empoderamento feminino na América Latina. Revista de Estudios Sociales [Online], v. 56, abr. 2016. Disponivel em: http://journals.openedition.org/revestudsoc/9863. Acesso em: 30 abr. 2019. https://doi.org/10.7440/res56.2016.06

MARTINS, EMERSON. Uma hermenêutica da homossexualidade: o fazer-se gay como prática politica de liberdade em cidades pequenas. 2017. Tese (Doutorado em Psicologia) - Centro de Filosofia e Ciências Humanas, Universidade Federal de Santa Catarina, Florianópolis, 2017.

ORLANDI, Eni Puccinelli. Análise de discurso: princípios e procedimentos. Campinas: Pontes, 2015.
PÊCHEUX, Michel. Semântica e Discurso: uma crítica à afirmação do óbvio. Campinas: Editora da Unicamp, 1997.

QUEVEDO, Marchiori Quadrado de. Do gesto de reparar a(à) gestão dos sentidos: um exercício de análise da imagem com base na análise de discurso. 2012. 253f. Dissertação. (Mestrado em Letras - Linguística Aplicada) - Universidade Católica de Pelotas, Pelotas. Pelotas, 2012.

STREY, Marlene Neves. Violência e gênero: um casamento que tem tudo pra dar certo. In: GROSSI, Patrícia Krieger. Violências e Gênero: coisas que a gente não gostaria de saber. Porto Alegre: EDIPUCRS, 2012. p. 51-72.

STREY, Marlene Neves; WERBA, Graziela. Longe dos olhos, longe do coração. In: GROSSI, Patrícia Krieger. Violências e Gênero: coisas que a gente não gostaria de saber. Porto Alegre: EDIPUCRS, 2012. p. 73-82.

ZOPPI FONTANA, Mónica Graciela; FERRARI, Ana Josefina. Mulheres em Discurso: gênero, linguagem e ideologia. Campinas, SP: Pontes Editores, 2017.

\section{Bruna Vitória Tejada}

Graduada em Letras pela Universidade Católica de Pelotas (UCPel, Pelotas, RS, Brasil), mestranda em Letras pelo Programa de Pós-Graduação em Letras da Universidade Federal de Pelotas (UFPel, Pelotas, RS, Brasil), bolsista CAPES.

\section{Luciana lost Vinhas}

Doutora em Letras pela Universidade Federal do Rio Grande do Sul (UFRGS, Porto Alegre, RS, Brasil), professora do Programa de Pós-Graduação em Letras da Universidade Federal de Pelotas (UFPel, Pelotas, RS, Brasil).

\section{Endereço para correspondência}

Bruna Vitória Tejada/Luciana lost Vinhas

Universidade Federal de Pelotas

Rua Gomes Carneiro, 1, Prédio B, andar térreo, sala 102

Centro, 96010610

Pelotas, RS, Brasil 